\title{
Orofacial Apraxia in Motor Neuron Disease
}

\author{
Patrícia Pita Lobo ${ }^{a}$ Susana Pinto ${ }^{c}$ Luz Rocha ${ }^{a, c}$ Sofia Reimão ${ }^{b}$ \\ Mamede de Carvalho ${ }^{a, c, d}$ \\ Departments of ${ }^{a}$ Neurosciences and ${ }^{b}$ Neuroimaging, Centro Hospitalar

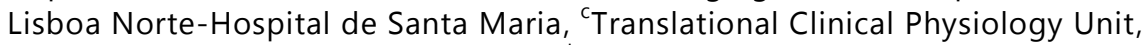 \\ Instituto de Medicina Molecular, and ${ }^{\mathrm{d}}$ Institute of Physiology, Faculty of Medicine, \\ University of Lisbon, Lisbon, Portugal
}

\section{Key Words}

Amyotrophic lateral sclerosis $\cdot$ Motor neuron disease $\cdot$ Orofacial apraxia $\cdot$ Primary lateral sclerosis · Tractography

\begin{abstract}
Introduction: Cognitive and behavioral impairments are considered to occur frequently in amyotrophic lateral sclerosis/motor neuron disease (MND). Rarely, apraxia has been reported in MND. Orofacial, or buccofacial, apraxia is characterized by a loss of voluntary control of facial, lingual, pharyngeal and masticatory muscles in the presence of preserved reflexive and automatic functions of the same muscles. Methods: We report a patient with MND who presented with spastic dysarthria and asymmetric orofacial apraxia. She progressed to frontotemporal dementia (FTD). Results: Clinical and neurophysiological examinations were suggestive of bulbar-onset MND-FTD. Tractography showed a reduction of fractional anisotropy in the centrum semiovale, corona radiata, corticomedullary pathway and inferior aspect of the medulla; the changes were more severe on the left side. To our knowledge, this is the first report of an asymmetric presentation of an apraxic syndrome in MND-FTD.
\end{abstract}

\section{Introduction}

Amyotrophic lateral sclerosis (ALS) is typically characterized by progressive degeneration of the motor neurons. Recent studies, including neuropsychological testing, imaging and neuropathology examination have demonstrated that frontal lobe involvement is common, although with variable clinical expression [1]. Diffusion-tensor MRI shows widespread involvement, including the temporal, parietal and occipital lobes [2,3].

Prof. Mamede de Carvalho

Department of Neurosciences, Hospital de Santa Maria

Av. Professor Egas Moniz

PT-1648-028 Lisbon (Portugal)

E-Mail mamedemg@mail.telepac.pt 
Apraxic syndromes are very rarely described in ALS [4, 5]. Orofacial, or buccofacial, apraxia (OFA) is characterized by a loss of voluntary control of facial, lingual, pharyngeal and masticatory muscles in the presence of preserved reflexive and automatic functions of the same muscles [6]. The typical patient fails to produce the correct movement in response to a verbal command or to imitate correctly a movement performed by the examiner. In terms of semiology, the patient is unable to blink (open and/or close) their eyes, smile, open and close the mouth, protrude the tongue, speak or swallow voluntarily, but they can be observed to smile if something interesting happens and opening the mouth automatically during yawning [6].

The brain anatomic basis for these specific disorders of voluntary movement is not fully defined, and apraxia remains an issue of considerable neurobiological as well as clinical interest. Anatomical evidence, chiefly from patients with stroke, has demonstrated several cerebral circuitries implicated in the voluntary control of orofacial and limb movements and in the production of apraxias [7-9]. For OFA, prefrontal areas (premotor and supplementary motor areas) and their subcortical projections are particularly implicated, and some studies are more precise in defining that this kind of apraxia is correlated with grey matter loss in the left middle frontal gyrus, namely Brodmann area 46 [10]. Whilst for limb apraxia, the areas more commonly involved are posterior areas, particularly the parietal lobe and its connections $[7,8]$.

\section{Case Report}

A 78-year-old right-handed woman was referred to our department with a history of slowly progressive slurred speech followed by mild difficulty in swallowing, which had started 3 years before our evaluation. She and her family denied other symptoms, like cognitive impairment or behavioral changes (she was working normally in her ambulatory pharmaceutical activity), respiratory symptoms, functional limitation, muscular weakness, as well as cramps or fasciculation. Her past medical and familial history were unremarkable, in particular stroke episodes were excluded. On the first neurological examination (in February of 2008), she was alert, with normal reading and writing ability; extraocular and facial movements, and pupillary and blink reflexes were preserved. We observed dysarthria with a spastic tongue, which had no atrophy or fasciculations. Sialorrhea was not observed. Jaw and limb tendon reflexes were very brisk and symmetric, plantar response was extensor on the left and questionable on the right side. Neck flexion was slightly weak ( 4 on the MRC scale) but strength was normal in the limbs, in which no atrophy or fasciculations were noticed. The patient's weight was stable. The rest of the neurological examination was normal; in particular we observed no change on sensory or cerebellar examination. Routine laboratory investigation was unremarkable; in particular CK level and thyroid function tests were normal, and an HIV test was negative. Brain MRI showed mild diffuse corticalsubcortical atrophy, considered normal for the patient's age. Electrodiagnostic investigation disclosed normal conduction study values, and needle sampling in limb and bulbar muscles (genioglossus and sternocleidomastoid on the right side) did not disclose loss of motor units or spontaneous activity. Transcranial magnetic stimulation revealed small motor responses from the left abductor digiti minimi $(0.4 \mathrm{mV}$; with $1.6 \mathrm{mV}$ on the right side) with slightly increased central conduction time in lower limbs. The diagnosis of motor neuron disease (MND) was established (features suggesting bulbar-onset primary lateral sclerosis).

Dysarthria slowly deteriorated and 1 year later the patient's communication was based on writing, which was grammatically preserved. There was no evidence of cognitive change; 
in particular her comprehension was normal, as evaluated by her written responses. She reported rapid onset of left facial paresis. On examination, all voluntary movements on the left side of her face were paretic (such as lifting eyebrows, closing the eyes or showing the teeth) on command or imitation (fig. 1a), but automatic movements, like smiling or coughing, where very symmetric and totally preserved (fig. 1b). Apraxia was tested but not observed in any other segments. A second electrodiagnostic study was normal, in particular facial nerve conduction, blink reflex and orbicularis oculi jitter were unremarkable. Although her mini-mental state status was normal (30/30), formal neuropsychological evaluation showed mild executive dysfunction. Repeated brain MRI did not reveal any major change as compared with the previous investigation. Diffusion-tensor imaging (tractography) showed reduction of fractional anisotropy (FA) in the centrum semiovale and corona radiata, corticomedullary pathway and inferior aspect of the medulla. Moreover, significant reduction of FA was observed in the transition between the precentral gyrus and premotor region bilaterally - with left-side predominance (fig. 2a-c).

Over the following 4 years she developed anarthria, aphagia (requiring percutaneous gastrostomy placement) and bilateral OFA. Her face become very paretic, without voluntary movements (fig. 3a); however, normal involuntary movements remained intact (smiling, yawning or sneezing) (fig. 3b). The remaining neurological features were stable, without weakness, muscle atrophy, respiratory symptoms or limb apraxia. Her family noticed behavioral changes (apathy and indifference to professional duties) and her written communication became poor, with agrammatism and limited vocabulary. Frontotemporal dementia (FTD) was diagnosed. Repeated electromyography did not find signs of lower motor neuron loss. She declined further investigations.

\section{Discussion}

Our patient presented with dysarthria but she progressed to prominent OFA that started asymmetrically and evolved to affect both sides. Later on, she showed signs of dementia, establishing the probable diagnosis of MND-FTD. Although this association has not been mentioned in recent years, in 1894 Strumpell [11] described the association of pseudobulbar syndrome and apraxia (the patient did not sustain eye closure or move the eyes on command, but had normal spontaneous movements). Dereux [12] reported Parinaud's syndrome with normal involuntary movements in a patient with ALS. Lapresle et al. [13] reviewed the previous reports and described 2 cases of facial automatic-voluntary motor dissociation in ALS patients. Abe et al. [5] reported 3 patients with ALS who had difficulty voluntarily opening or closing their eyelids, associated with disturbance in the executive function. Pinto et al. [14] reported an ALS patient with respiratory apraxia, without clinical dementia or other apraxic syndromes. Duffy et al. [15] reported progressive apraxia of speech as a sign of ALS, which consisted of impaired capacity to plan commands that direct speech movements.

OFA is more frequently observed with left hemisphere lesions, in particular involving the frontal and central operculum, insula, centrum semiovale and basal ganglia [8]. Studies in macaques indicate that connections between the rostral supplementary motor area and the primary motor cortex are important for less automatic, 'unfamiliar' sequences, such as repeating complex facial movements. Tractography in this patient showed a significant FA decrease in the transition between the premotor region and primary motor cortex bilaterally, but with left-side predominance. These imaging abnormalities support the anatomical 
topography related to OFA [7-10]. Our observation expands the phenotypic expression of MND-FTD.

\section{Acknowledgements}

This work was supported by 'Fundação para a Ciência e Tecnologia' - JPND/0002/2011.

\section{References}

1 Giordana MT, Ferrero P, Grifoni S, Pellerino A, Naldi A, Montuschi A: Dementia and cognitive impairment in amyotrophic lateral sclerosis: a review. Neurol Sci 2011;32:9-16.

-2 Senda J, Ito M, Watanabe H, Atsuta N, Yoshinari Kawai Y, Katsuno M, Tanaka F, Naganawa S, Fukatsu H, Sobue G: Correlation between pyramidal tract degeneration and widespread white matter involvement in amyotrophic lateral sclerosis: a study with tractography and diffusion-tensor imaging. Amyotroph Lateral Scler 2009;10:288-294.

-3 Wang S, Melhem ER, Poptami H, Woo JH: Neuroimaging in amyotrophic lateral sclerosis. Neurotherapeutics 2011;8:63-71.

4 Abrahams S, Goldstein L, Al-Chalabi A, Pickering A, Morris R, Passingham R, Brooks DJ, Leigh PN: Relation between cognitive dysfunction and pseudobulbar palsy in amyotrophic lateral sclerosis. J Neurol Neurosurg Psychiatry 1997;62:464-472.

-5 Abe K, Fujimura H, Tatsumi C, Toyooka K, Yorifuji S, Yanagihara T: Eyelid 'apraxia' in patients with motor neuron disease. J Neurol Neurosurg Psychiatry 1995;59:629-632.

6 Bakar M, Kirshner H, Niaz F: The opercular-subopercular syndrome: four cases with review of the literature Behav Neurol 1998;11:97-103.

-7 Raade AS, Rothi LJG, Heilman KM: The relationship between buccofacial and limb apraxia. Brain Cogn 1991;16:130-146.

-8 Pramstaller PP, Marsden CD: The basal ganglia and apraxia. Brain 1996;119:319-340.

9 Ackermann H, Riecker A: The contribution of the insula to motor aspects of speech production: a review and a hypothesis. Brain 2004;89:320-328.

10 Rohrer JD, Rossor MN, Warren JD: Apraxia in progressive nonfluent aphasia. J Neurol 2010;257:569-574.

-11 Strumpell A: Ueber einen Fall von primärer systematischer Degeneration der Pyramidenbahnen mit den Symptomen einer allgemeinen Spastischen Lähmung. Dtsch Z Nervenheilk 1894;5:225-246.

12 Dereux J: Sclérose latérale amyotrophique avec syndrome de Parinaud et blépharospasme. Rev Neurol 1930;6:675-679.

13 Lapresle J, Salisachs P: Phénomènes de dissociation volontaire et automatic-réflexe au niveau de certains muscles innerves par les paires craniennes dans deux observations de sclérose latérale amyotrophique. Rev Neurol 1976;132:157-161.

14 Pinto S, Pinto A, Atalaia A, Peralta R, Carvalho M: Respiratory apraxia in amyotrophic lateral sclerosis. Amyotroph Lateral Scler 2007;8:180-184.

15 Duffy J, Peach R, Strand E: Progressive apraxia of speech as a sign of motor neuron disease. Am J Speech Lang Pathol 2007;16:198-208. 


\section{Case Reports in Neurology}

\begin{tabular}{l|l}
\hline Case Rep Neurol 2013;5:47-51 \\
\hline DOI: $\underline{10.1159 / 000349895}$ & $\begin{array}{l}\text { C 2013 S. Karger AG, Basel } \\
\text { www.karger.com/crn }\end{array}$ \\
\hline
\end{tabular}

Pita Lobo et al.: Orofacial Apraxia in Motor Neuron Disease
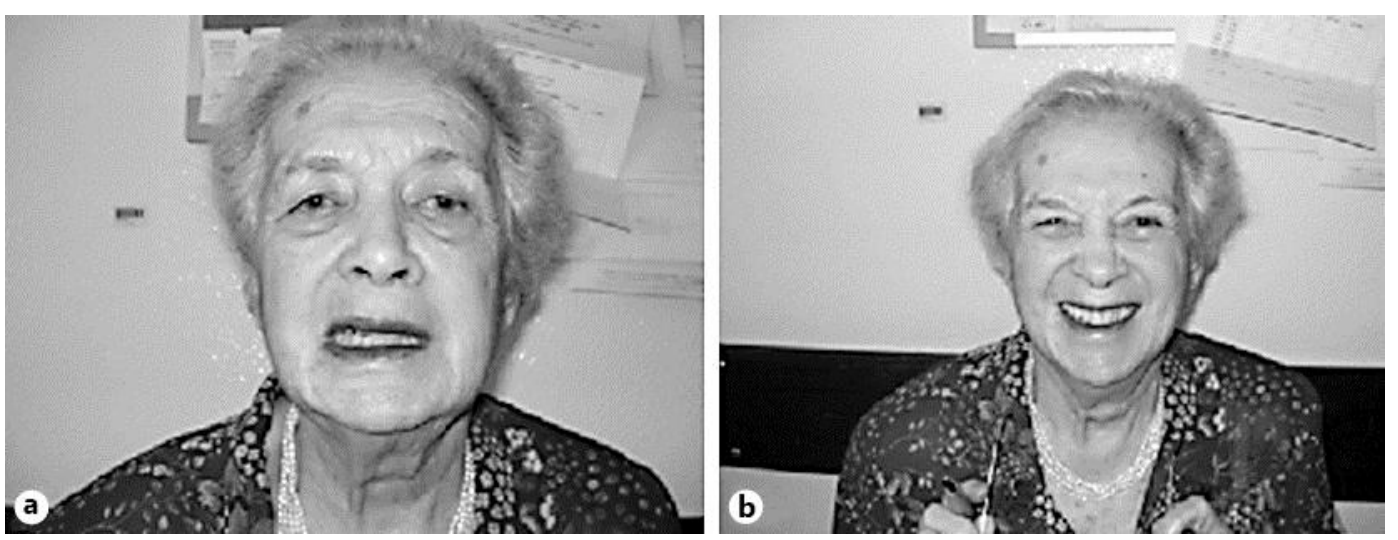

Fig. 1. a On the command 'show your teeth', left facial paresis is seen. b Smiling without asymmetry after a joke.
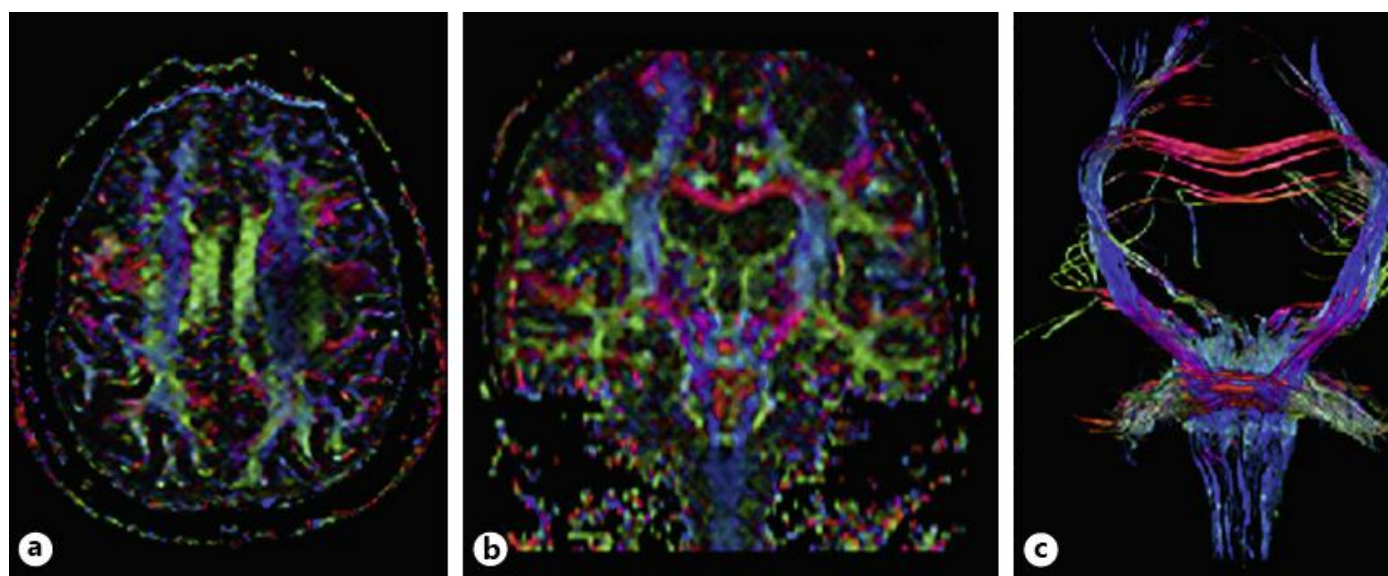

Fig. 2. Axial (a) and coronal (b) diffusion tensor imaging (DTI) color maps showing diffuse color intensity decrease in the pyramidal tract, with marked decrease in the left precentral gyrus, premotor region and corona radiata. DTI fiber tractography (c) with ROI placed in the pons showing asymmetry of fiber integrity in the left corona radiata/centrum semiovale.
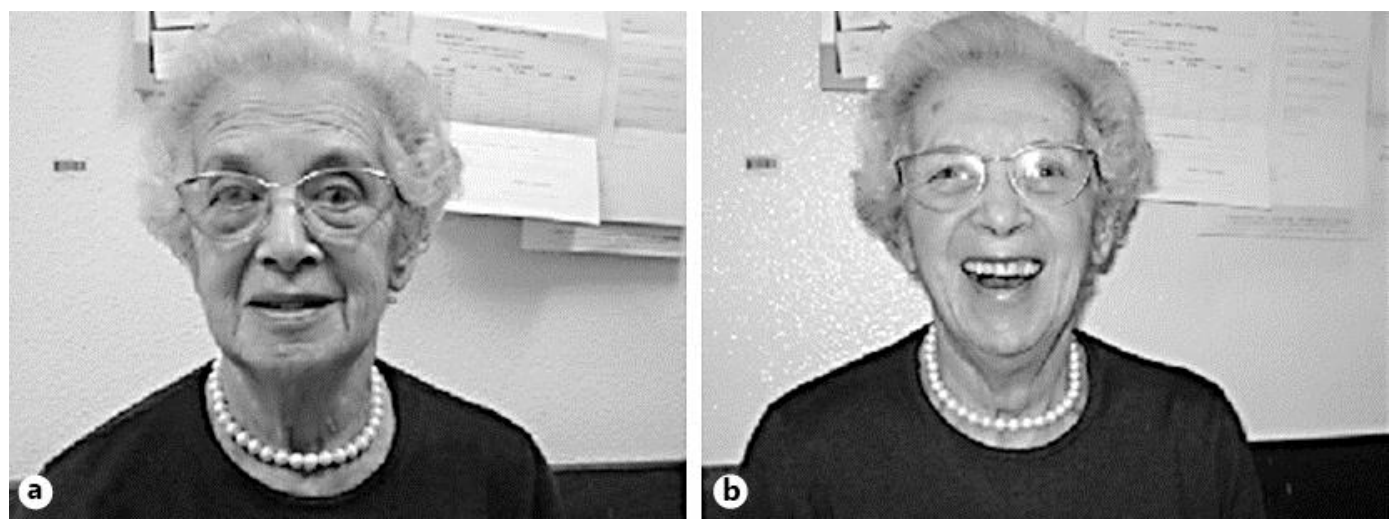

Fig. 3. a On the command 'show your teeth', bilateral facial paresis is seen. b Smiling after a joke. 